Journal of Environmental Management

December 2017, Volume 204 Issue Part.1 Pages 404-412

http://dx.doi.org/10.1016/i.jenvman.2017.08.046

http://archimer.ifremer.fr/doc/00399/51048/

(c) 2017 Elsevier Ltd. All rights reserved

\title{
Survival of European plaice discarded from coastal otter trawl fisheries in the English Channel
}

\author{
Morfin Marie ${ }^{1,{ }^{*}}$, Kopp Dorothee ${ }^{1}$, Benoît Hugues P. ${ }^{2}$, Méhault Sonia ${ }^{1}$, Randall Peter ${ }^{3}$, Foster Robert \\ ${ }^{3}$, Catchpole Thomas ${ }^{3}$
}

${ }^{1}$ IFREMER, Unité de Sciences et Technologies halieutiques, Laboratoire de Technologie et Biologie Halieutique, 8 rue François Toullec, F-56100, Lorient, France

${ }^{2}$ Gulf Fisheries Centre, Fisheries and Oceans Canada, Moncton, NB, E1C 9B6, Canada

${ }^{3}$ Centre for Environment, Fisheries and Aquaculture Science, Lowestoft, United Kingdom

*Corresponding author : Marie Morfin, email address : $\underline{\text { mariemorfin@hotmail.com }}$

\begin{abstract}
:
Species that have a high likelihood of surviving the discarding process have become great concern since the European Union reformed the Common Fisheries Policy and enacted a landing obligation prohibiting the discarding any individuals of species under quota. Among species presenting an elevated survival potential, plaice (Pleuronectes platessa) is one of the most discarded in the coastal otter trawl fishery in the English Channel.
\end{abstract}

The objective of this study is to provide the most reliable estimates of plaice survival after release in commercial conditions, and to identify the factors that influence survival rates. A captivity experiment was conducted in January-February in the English fishery to assess the survival of discarded plaice as a function of a semi-quantitative index of fish vitality, which has been demonstrated to be a good proxy of fish survival in comparable fishing and environmental conditions. This study examined the potential of this index to estimate discard survival in three trials from the English and French fisheries and at three different seasons. The vitality index was then used to analyse the influence of several factors (fishing practices, environmental conditions and fish biological characteristics) on the discard survival.

The survival rates for plaice were accurately estimated at $62.8 \%$ in January-February, $66.6 \%$ in November and $45.2 \%$ in July. While these rates remained substantial whatever the fishing, environmental or fish biological conditions, the time fish spent on the deck, the bottom and air temperatures, the tow depth and the fish length had a significant influence on plaice survival. In practice, plaice survival could be enhanced by releasing the fish early during catch sorting and avoiding exposure to extreme air temperatures. 


\section{Highlights}

- Survival rates of European plaice in the English Channel otter trawl fishery. Between 45 and $67 \%$ of plaice survived depending on seasons and vessel. Semi-quantitative vitality index is a relevant proxy of plaice discard survival. Handling duration, temperature and fish length were the main survival drivers. Release back to the sea during catch sorting substantially increases survival.

Keywords : Landing obligation, Pleuronectes platessa, Vitality, Captivity experiment, Discard survival analysis, Bottom trawl 
39 The European Union recently modified its Common Fisheries Policy (CFP) and has enacted a landing

40 obligation under which discarding of species under quota management will be prohibited (Official

41 Journal of the European Union, December $28^{\text {th }}$ 2013). However, the regulation acknowledges that

42 there may be net benefits to conservation of allowing discarding in certain instances where there is

43 the likelihood of successful live release of unwanted catches. Specifically, article 15 paragraph 4(b) of

44 the regulation allows for the possibility of exemption from the landing obligation for "species for which

45 scientific evidence demonstrates high survival rates, taking into account the characteristics of the gear,

46 of the fishing practices and of the ecosystem". While no threshold has been defined for a "high survival

47 rate", exemptions will be allowed for species and fisheries where survival levels are assessed to be

48 sufficiently high. In this context, there has been a recent enhanced focus on the estimation of discards

49 survival and the identification of stressors involved in discard mortality in European marine fisheries

50 (Breen et al., 2012; Depestele et al., 2014; Méhault et al., 2016; UhImann et al., 2016).

51 European otter trawl fisheries have received particular attention given the large amounts of discards

52 they generate (Cornou et al., 2015). Furthermore, capture in trawls is recognised to be stressful for

53 fish, causing injuries such as abrasion, crushing and scale loss, and leading to exhaustion by sustained 54 swimming (Davis, 2002), with severity depending on the gear type and how it is fished (e.g. haul 55 duration, towing speed) (Macbeth et al., 2006; Wassenberg et al., 2001). When the trawl is hauled 56 back, overcrowding of fish in the net, along with changes in environmental conditions such as pressure, 57 salinity and temperature may induce additional stress and injuries (Davis, 2002; Harris and Ulmestrand,

58 2004; Tenningen et al., 2012; Uhlmann and Broadhurst, 2015). As a result, many individuals may be 59 already dead upon arrival on deck. For those that survive the catching process, air exposure during 60 catch handling is amongst the strongest stressors contributing to mortality (Benoît et al., 2013, 2010;

61 Castro et al., 2003; Macbeth et al., 2006). Temperature and light conditions have also been found to 62 influence survival (Davis and Olla, 2002; Giomi et al., 2008). Among fish that are still alive when thrown 
back to the sea, weakened individuals are at greater risk of avian and marine predation (Depestele et al., 2016). Depending on species and physiological status of the fish (sex, reproductive status, size), individuals may withstand stress and injury differently, resulting in variable post-release survival of discards (Benoît et al., 2013; Broadhurst et al., 2006; Davis and Olla, 2002; Depestele et al., 2014).

Discard mortality is generally assessed by either tagging or captivity experiments. While mark and recapture tags can produce discard survival estimates, this is only possible as part of a substantial and ongoing tagging programme. Data storage and acoustic tags offer alternative methods but these are generally only suitable for larger specimens owing to the current size of the technology, and are relatively expensive approaches (e.g., Capizzano et al., 2016). Captivity experiments are generally the best option for cases where tagging is not feasible. In these experiments it is often possible to track the fate of individual fish and to measure exact or approximate mortality times. The death may occur immediately so that it can be observed directly on-board, or in a delayed period, if the fish does not recover from its injuries. Delayed mortality associated with capture and discarding has been shown to occur typically on the time scale of days to weeks (Benoît et al., 2015, 2012). In the absence of other sources of mortality, mortality of a group of discarded fish reaches an asymptote, when no further mortalities associated with the catch and discard process are observed. The point at which observed mortalities reach asymptote represents the discard survival rate.

It is also possible to consider the effects on mortality of an individual's biological characteristics (e.g., length, sex) and the capture and handling conditions it experienced. This can be done using direct observation (e.g., Neilson et al., 1989) or indirectly by first considering mortality as a function of a vitality indicator and then the vitality indicator as a function of covariates (e.g., Benoît et al., 2012; Depestele et al., 2014). Vitality indicators typically involve the degree of injury sustained by an individual and impairment to its reflexes, which individually and jointly have been found to be good predictors of survival (Benoît et al., 2010, 2012; Davis, 2010; Davis and Ottmar, 2006). The indirect approach is advantageous in that it is possible to model vitality in a fishery, thereby integrating over the various conditions that exist in that fishery, to produce discard mortality estimates that are representative (e.g., Benoît et al., 2012). The approach requires assumptions, detailed below, on the relationship between vitality and survival and on the conditions experienced by the fish. However, the alternative is to generate direct observations of survival across all these conditions which is prohibitively costly due to logistic (e.g., number of vessels and environmental conditions involved) and budgetary constraints.

The present study considers the mortality of European plaice (Pleuronectes platessa) discarded in coastal otter trawl fisheries in the English Channel. While discarded amounts of European plaice are substantial in this fishery (48-76\%, Cornou et al., 2015), this species has an elevated potential to survive 
the catching and handling processes (Morfin et al., 2017). Here we aim to enhance the evidence on discard survival for plaice in this fishery so that its suitability as a candidate for exemption from the landing obligation can be better assessed. Also, the influence of the fishing conditions was analysed to identify possible measures that could enhance discard survival in the fishery.

\section{MATERIAL AND METHODS}

Firstly, discard survival as a function of a semi-quantitative index of fish vitality was estimated from a captivity experiment. Then the survival rate in the commercial conditions of the coastal otter trawl fishery in the English Channel was estimated for three different seasons, by combining the survival estimates in captivity with vitality data that were representative of the fishery in those seasons.

\subsection{Captivity experiment}

\subsubsection{Plaice sampling in commercial conditions}

The captivity experiment utilised catches taken aboard a $14.98 \mathrm{~m}$ English commercial twin-rig trawler in January-February 2015. The vessel operated from the port of Brixham in the English Channel (ICES subarea VIIe) to exploit Lyme Bay lemon sole and squid fishery. Twenty hauls were performed in ten days under commercial fishing conditions representative of the normal activity of the fleet working in this area (Catchpole et al., 2015). The crew conducted one-day trips of two tows of up to 5 hours' duration. Each trawl had a footrope length of $22 \mathrm{~m}$, and cod ends were $90 \mathrm{~mm}$ mesh made of a $4 \mathrm{~mm}$ diameter single braid twine. Water depths were generally shallow $(26-46 \mathrm{~m})$ and the hauling process usually took about 20 minutes. Standard practice is to push discarded fish through the scuppers back into the sea as the catch is being sorted on the deck. The deck area was partially sheltered, and a $1 \mathrm{~m}$ high railing reduced exposure of the catch to direct sunlight and to the wind. It was not possible to conduct captive observation experiments with French trawlers owing to their limited size (typically $10.3 \mathrm{~m}$ ) and vessel layout, which precludes housing holding tanks on-board. Nonetheless, geographic proximity and similarity in fishing conditions between the English and French fleets are such that the results from the English vessel were expected to be relevant to the French vessels.

A sample of up to 40 plaice was randomly selected from each haul (1040 individuals in total) throughout the sorting period (typically 30 minutes), to assess their vitality status at the moment they would normally be released to the sea. Fish vitality was visually assessed rapidly ( $10 \mathrm{sec}$ ), according to a four-level ordinal index based on fish injuries and body movement (Table 1). 


\begin{tabular}{lll}
\hline Vitality & Code & Description \\
\hline 'Excellent' & 1 & $\begin{array}{l}\text { Vigorous body movement; no or slight injuries: minor bleeding, minor fin fraying, } \\
\text { minor scale loss }(<5 \%) \text {, minor abrasion }\end{array}$ \\
& 2 & $\begin{array}{l}\text { Moderate body movement; responds to touching/prodding; injuries including } \\
\text { minor bleeding, minor fin fraying, minor scale loss, minor scratches, minor net } \\
\text { 'Good' }\end{array}$ \\
& 3 & $\begin{array}{l}\text { marks, minor abrasion, minor bruising } \\
\text { scale loss, scratches, net marks, abrasion, wounds, organs exposed, bruising }\end{array}$ \\
& & No body or head complex movements (no response to touching or prodding) \\
\hline
\end{tabular}

Table 1. Description of the categories used to score visually the pre-discarding vitality of individual fish 127 (adapted from Benoît et al., (2010))

\subsubsection{Technical and environmental conditions}

129 A series of variables related to the fishing operation, the environmental conditions and the fish 130 biological characteristics were also recorded to determine their influence on discard survival, 131 including: the tow duration $(\mathrm{min})$, the average tow depth $(\mathrm{m})$ and sea water temperature $\left({ }^{\circ} \mathrm{C}\right)$; on the 132 deck, the catch weight $(\mathrm{kg})$, the air temperature $\left({ }^{\circ} \mathrm{C}\right)$, the wind force (Beaufort scale) as well as the 133 total fish length ( $T L$ in $\mathrm{cm}$ ).

\subsubsection{Monitoring in captivity}

A subsample from each vitality group was then selected for the captivity experiment from the full range of vitality levels and fish lengths. A total of 348 plaice (40 moribund, 101 poor, 115 good and 92 excellent) from 17 hauls, were placed into a vertical stack of five holding tanks $(80 \times 60 \times 20 \mathrm{~cm})$ supplied with continuous water flow (3-4 l/min). Each tank was stocked with up to eight plaice of the same vitality level with different lengths so that they can be individually identified. Once the vessel arrived in Brixham harbour (after less than 12h), it took approximately 15 minutes to transfer fish in tubs to onshore tanks (same dimension), also supplied with constant seawater flow (Catchpole et al., 2015).

142 Tanks were examined every $12 \mathrm{~h}$ for an observation period ranging from 66 to $133 \mathrm{~h}$. Fish that

143 responded to a tail grab on inspection were declared alive. Fish that showed sustained absence of 144 response (body or opercular movement) to touching or prodding were declared dead and removed 145 from the tank. Seawater and air temperatures were recorded at each routine examination of fish. 
147 To source true control specimens for survival assessments, i.e. those which are the same in all ways 148 other than having gone through the catch and discard process, is challenging. A control experiment was undertaken to assess whether captivity in the onshore holding tanks induced mortality. At the CEFAS laboratory Lowestoft, eighteen aquarium-acclimatised plaice were introduced into the experimental onshore holding tanks filled with water at the same temperature and salinity as in the aquarium, and held for 72 hours. The specimens underwent vitality assessments at the beginning and end of the period and no deterioration in health was observed. This provided confidence that the onshore tanks did not adversely affect the health of the captive fish. It was not possible to source control fish at the time the treatment fish were collected; neither was it possible to test the effect on health on the on board tanks, which may have been influenced by the range of environmental conditions experienced.

In the absence of genuine controls, the fate and final condition of treatment fish that were initially assessed to be in pristine condition (no reflex impairment or injuries) were examined in isolation. The assumption was that if the experimental set-up had no effect on the health of the captive fish, then these fish would survive in pristine condition until the end of the experiment. There were 14 fish initially assessed to be in pristine condition, from five different days fishing, most from the first haul of the day. Of these, there was one fatality, a survival rate of $93 \%$. The final assessments after 167-342 hours in captivity showed no reflex impairment or injury in the survivors, providing further confidence that experimental induced mortality was limited.

\subsection{Survival in captivity depending on vitality}

167

\subsubsection{Weibull-mixture model}

Longitudinal data track the same sample at different points in time. For discard survivability studies, a plausible description of the results is that the proportion of fish surviving will gradually decrease and then reach an asymptote, with a proportion of fish surviving the capture, handling and release process. Modelling this process and predicting the survival probability requires an extension of standard survival analysis models, as these assume that the discard-related mortality must extend until survival is zero i.e. standard models fit a curve that extends until all the fish are dead rather than having a plateau related to survival.

Here we use a parametric, Weibull mixture distribution model (Benoît et al., 2012, 2015; Farewell, 1982; Gu et al., 2011). This longitudinal analysis of captivity data via the cumulative distribution of death events (survival function) is useful as the time of death of individuals still alive at the end of the experiment is unknown. These individuals can therefore be considered as right-censored observations. Furthermore, the observation periods varied between individuals from 66 to 133 hours as they were 
not introduced into the holding tanks at the same time. Conversely to standard survival models assuming that all uncensored and right-censored individuals will die according to the same probability function, cure rate or mixture distribution models allow that some unknown proportion of individuals survive. These models include a binary random latent variable of the fish discard survival status, $Y \sim B(\pi)$, where $\pi$ is the probability that a fish was mortally affected by capture and discarding. For those fish, their times of death $T$ were assumed to follow a two parameter Weibull distribution as it provides a reasonable model according to the shape of the non-parametric Kaplan-Meier curves (Kaplan and Meier, 1958). For the fish that survived, their lifetime was assumed infinite as the natural mortality was considered negligible at the time scale of the experiment. The resulting survival function, i.e. the probability that an individual survived longer than the time period $t$, is expressed as follow:

Eq 1

$$
P(T>t)=S(t)=1-\pi+\pi S_{A}(t)
$$

Eq $2 \quad S_{A}(t)=1-\exp \left(-(\alpha t)^{\gamma}\right)$

where $S_{A}(t)$ is the "short-term" survival function for the affected group, and $\alpha>0$ and $p>0$ are respectively the scale and shape parameters of the Weibull distribution. As stated, the mortality rate is expected to decrease with time and converge to an asymptote 1- $\pi$, i.e. the discard survival probability.

While discard survival probability is expected to be correlated with vitality, the shape of survival functions of affected individuals may also depend on the vitality groups. Therefore, the vitality index was tested as a categorical covariate on the three parameters $(\alpha, \gamma$ and $\pi)$ describing the survival model, resulting in eight potential models. Model parameters were estimated by maximisation of the model likelihood using a quasi-Newton optimisation algorithm (Byrd et al., 1995). The observed death times were approximated as the mid time between the last time the fish was observed alive and the first time the fish was declared dead.

\subsubsection{Model selection and assessment}

Models were ranked according to Akaike's Information Criterion (AIC), a measure of parsimony (Akaike, 1981). Model fit was assessed visually by superimposing the predicted survival curves on nonparametric Kaplan-Meier curves. As the survival models were to be used to predict the survival rate from vitality data collected in other samples, the selected model was required to have good predictive performance. This was measured by a leave- $p$-out cross-validation procedure, with $p$ equal to about $10 \%$ of the sample size (Arlot and Celisse, 2010). Test samples were drawn according to different vitality distributions (from 10 to $90 \%$ of each vitality group) to assess the prediction error independently of the sample vitality distribution. The prediction error was measured as the absolute difference between the observed and predicted survival rate at $120 \mathrm{~h}$, and adjusted for right-censored 
data in the same manner as the Brier score (Gerds and Schumacher, 2006). This score is comprised between 0 and 1 and a value close to 0 means a perfect prediction. Confidence intervals of the survival rates in each vitality group were estimated by a parametric bootstrap method described in Supplementary Material S1.

\subsection{Vitality sampling in the French fishery}

The vitality of discarded plaice in the French commercial fishery was sampled on-board a commercial trawler operating in the eastern English Channel (EC; ICES subarea VIId) and targeting multispecies fish assemblages. Two observers participated in commercial fishing trips aboard the vessel prior to the sampling trips to ensure that the sampling protocols would not induce any changes in fishing or catch handling practices by the harvesters. Two at-sea trials were then conducted during five twoday trips by the same two experienced on-board observers in November 2014 (27 hauls) and July 2015 (18 hauls). For each haul, discarded plaice were randomly sampled once the catch sorting began and for a maximum time period of 50 minutes so that the duration of air exposure of fish was representative of the commercial fishing practices. Each individual was measured and its vitality score determined according to the same four classes described in Table 1, resulting in a total of 396 and 367 plaice observed in November and July respectively.

The total handling time was recorded (from cod-end retrieval to when the fish was assessed for vitality status, in minutes), the air temperature and the sea bottom temperature $\left({ }^{\circ} \mathrm{C}\right)$, the tow depth $(\mathrm{m})$ and duration (min.), and the presence/absence of injury-inducing elements in the catch such as stones and oysters (Table 2). The catch weight in the French fishery could not be assessed as the catch was spread on the deck before being sorted and the discard amount was highly variable, but it was never heavier than one ton.

\subsection{Discard survival in the English Channel}

The average survival probability of plaice discarded from each trial was estimated by combining their vitality distributions and the vitality-dependent survival probabilities estimated from the captivity experiment (Benoît et al., 2012):

Eq $3 \hat{R}=\frac{1}{m} \sum_{s=1}^{m} \sum_{v=1}^{4} w_{s, v}\left(1-\hat{\pi}_{v}\right)$

Where $m$ is the number of hauls surveyed and $w_{s, v}$ is the proportion of individuals in haul $s$ with vitality level $v$. The confidence intervals of the survival rates were estimated by a two levels bootstrap method to account for uncertainty in both vitality-dependent survival from the captivity experiments and vitality distributions from the French fishery sampling as described in Supplementary Material S1. 


\subsection{Proxy assumption}

The proposed methodology to estimate discard survival relies on two key assumptions, that the vitality index is highly correlated with survival probability, and the vitality-dependent survival rates are independent of the external conditions for both vitality and captivity experiments or that any dependence can be predicted. In other words, survival depends only on vitality or measured covariates such that the results of the experiments conducted aboard the English trawler can be applied to the vitality sampling from the French fishery. The validity of these assumptions was explored using the mixture Weibull model described in section 2.2., to which the external drivers were added to the parameter $\pi$ as covariates to evaluate their influence on the model. AIC and prediction performance were calculated to compare and evaluate these models.

\subsection{Drivers of discard survival}

A second objective was to analyse the influence of several factors (fishing practices, environmental conditions and fish biological characteristics) on the discard survival. The relationship was set using vitality data as they could be collected in greater quantities and in conditions representative of each trial.

\subsubsection{Relationship between vitality index and potential survival drivers}

The factors measured in the vitality experiments related to the fishing practices (haul depth, tow duration and air exposure), the physical environment (the thermal shock, i.e. the absolute difference between the sea bottom and air temperatures, the air temperature and presence/absence of injuryinducing elements in the catch) and the fish biology (fish TL) were tested for their potential influence on plaice vitality. This was analysed via a parametric model relating these factors as linear or second order combinations of covariates to the vitality index as response variable. To account for the ordinal nature of the vitality index, a proportional-odds ordered logit model (McCullagh, 1980) was tested (see Benoît et al., (2010) for an application to discard vitality data). Furthermore, a random effect was tested at the haul level to account for the potential additional variability between hauls. The ordinal nature of the vitality index was accounted by scoring the 'Excellent' to 'Moribund' status by 1 to 4 values and modelling its cumulative distribution function, linked to the explanatory part by a logistic function. Formally, for each individual $j$ from haul $i$ :

Eq $4 \operatorname{logit}\left(P\left(V_{i j} \leq v\right) \mid X_{i j}\right)=\alpha_{v}+u_{i}+X_{j}^{\prime} \boldsymbol{\beta} \quad$ for $\quad v=1, \ldots, 3$

where $X$ is the design matrix of covariates, $\alpha_{v}$ the intercepts, $u_{i} \sim N\left(0, \sigma^{2}\right)$ the random effect and $\boldsymbol{\beta}$ the vector of fixed effects. All the linear combinations of covariates as well as the interactions that were felt to potentially be important $a$ priori were tested, namely ones including the interactions with the 
air exposure. Models were fitted with the R package 'ordinal' (Christensen, 2015), the random effect was tested on the saturated model including all covariates by a one-tailed chi-square test and the fixed effects selected by AIC.

\subsubsection{Model interpretation: relationship between discard survival and selected factors}

The marginal predicted probability that a discarded plaice belongs to a given vitality group $v$ depending on each selected covariate $X^{i}(i=1, \ldots, p)$ was calculated by setting all the other selected covariates to their means:

Eq $5 P\left(V=v \mid X^{i}, X^{-i}=\bar{X}^{-i}\right)=P\left(V \leq v \mid X^{i}, X^{-i}=\bar{X}^{-i}\right)-P\left(V \leq v-1 \mid X^{i}, X^{-i}=\bar{X}^{-i}\right)$

These relationships were then combined with the vitality-dependent survival estimated from the captivity experiment to quantify the effect of each selected covariate $X^{i}$ on the estimated survival probability $\hat{R}$ :

Eq $6 \hat{R}(x)=\sum_{v=1}^{4} \hat{P}\left(V=v \mid X^{i}=x, X^{-i}=\bar{x}^{-i}\right)\left(1-\hat{\pi}_{v}\right)$

\section{RESULTS}

\subsection{Fishing conditions of the three trials}

290

The fishing conditions and fish length of sampled plaice for vitality assessment were similar between the November and July trials, except for the air and seawater temperatures (Table 2). The tows were slightly deeper $(10 \mathrm{~m})$ and the tow durations were much longer (about 2.8 times longer) in the English trial than in the French trials. Both seawater and air temperatures also had different ranges, but the difference between the seawater and the air were similar. The individual air exposure was not measured in the January trial but the fish were observed throughout the catch sorting in all trials and sorting durations were similar. Fish length distributions were similar, although in the English data there were larger specimens.

\begin{tabular}{llll}
\hline & January - February & November & July \\
\hline ICES area & VIle & VIId & VIId \\
Vessel & 'Guiding Light III' & 'Mon petit Célestin' & 'Mon petit Célestin' \\
Vessel length $(\mathrm{m})$ & 14.98 & 10.95 & 10.95 \\
Gear type & Twin Rig Otter trawl & Otter trawl & Otter trawl \\
Net mesh size $(\mathrm{mm})$ & 90 & 90 & 90 \\
Fishing days & 10 & 6 & 5
\end{tabular}




\begin{tabular}{|c|c|c|c|}
\hline $\begin{array}{l}\text { Nb of plaice observed in } \\
\text { captivity (hauls) }\end{array}$ & $348(17)$ & 0 & 0 \\
\hline $\begin{array}{l}\text { Nb of plaice assessed for } \\
\text { vitality (hauls) }\end{array}$ & 1040 (19) & $396(25)$ & $367(18)$ \\
\hline \multicolumn{4}{|c|}{ Measured conditions at the individual level: Mean, Min-Max, (CV in \%) } \\
\hline Towing speed (knots) & NA & $3.0,2.5-3.5(N A)$ & $3.0,2.5-3.5(N A)$ \\
\hline Depth $(\mathrm{m})$ & $36.2,26.0-44.0(15)$ & $22.2,18.6-26.9(10)$ & $19.0,15.7-25.1(17)$ \\
\hline Tow duration (min) & $270,240-305(5)$ & $114,45-141(20)$ & $93,60-115(14)$ \\
\hline Bottom temperature $\left({ }^{\circ} \mathrm{C}\right)$ & $9.4,-(5)$ & $13.9,13.4-14.1(6)$ & $17.9,17.4-18.3(12)$ \\
\hline Air temperature $\left({ }^{\circ} \mathrm{C}\right)$ & $7.1,4.0-13.5(35)$ & $11.3,9.2-12.2(6)$ & $18.1,14.0-21.2(12)$ \\
\hline Thermal shock $\left({ }^{\circ} \mathrm{C}\right)$ & $2.9,0.5-5.0(62)$ & $2.6,1.3-4.5(27)$ & $1.8,0.4-3.7(61)$ \\
\hline $\begin{array}{l}\text { Injury-inducing elements } \\
(0 / 1)\end{array}$ & NA & $0.15,0-1(238)$ & $0.61,0-1(80)$ \\
\hline Catch weight $(\mathrm{kg})$ & $2340,1302-6604(50)$ & $N A,<1000$ (NA) & $N A,<1000$ (NA) \\
\hline Air exposure (min) & NA & $36.4,7.0-87.0(51)$ & $36.4,7.0-64.0(41)$ \\
\hline Plaice TL (cm) & $27.7,19.0-60.0(16)$ & $24.1,20-30.0(8)$ & $26.0,18.0-31.0(10)$ \\
\hline
\end{tabular}

Table 2. Description of the fishing conditions during the vitality assessment for the three seasonal trials.

\subsection{Survival in captivity depending on vitality}

301

302

303

304

305

306

307

308

309

310

311

312

313

While it was not possible to source control specimens when the holding tanks were in-situ to contain the treatment fish, the survival of pristine treatment fish and of control fish held prior to the experiment, indicated that the holding tanks did not induce notable levels of mortalities.

The most parsimonious survival model included the effect of vitality index on each of the three parameters of the Weibull mixture model $(\alpha, \gamma$ and $\pi)$. The predicted survival functions for each vitality level corresponded with Kaplan-Meier curves, confirming a good fit of the model (Figure 1). The predictive performance of the model was $61 \%$ better than the neutral model without any explanatory variable and the expected prediction error was estimated at 0.08 (Table 3). The shape parameter $y$ was systematically greater than one and linearly correlated to the vitality level, which indicates that the instantaneous death rate increased with time in all the groups and this increase was correlated to the vitality. At $110 \mathrm{~h}$, the average monitoring time period, the survival functions had converged at more than $95 \%$ to their asymptote, except for the 'Poor' group which survival function converged at $86 \%$ (Figure 1). Furthermore, the fish still alive at the end of the monitoring period were all assessed in 'Excellent' or 'Good' status, suggesting that the monitoring period was sufficiently long to observe any 

vitality index, from 0.90 for the 'Excellent' class to 0.04 for the 'Moribund' class (Table 3).

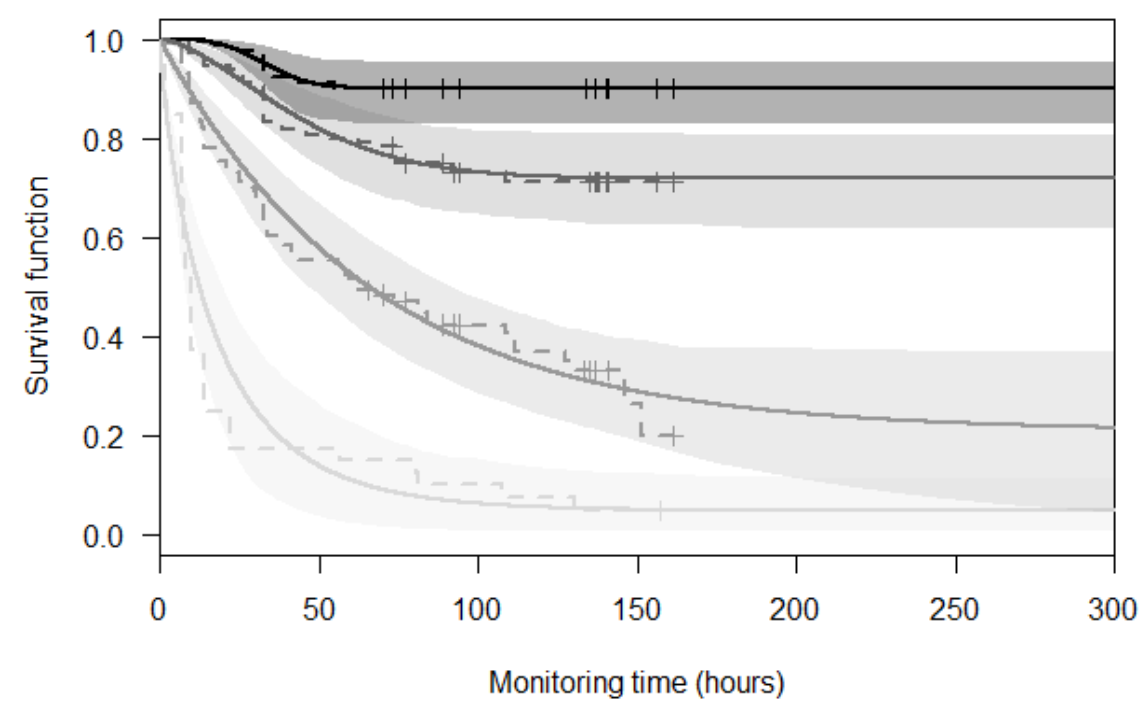

317

318 Figure 1. Curves of survival functions from captivity data estimated by vitality level ('Excellent' to 319 'Moribund' groups in black to light grey colours) using the non-parametric Kaplan-Meier method 320 (dashed lines) and the parametric mixture Weibull method (solid lines). Shaded areas are the mixture 321 Weibull 95\%-confidence intervals.

\section{3.3. Discard survival}

\section{$323 \quad$ 3.3.1. Proxy assumption}

324 A combination of both vitality and external variables produced the most parsimonious model, 325 suggesting that some variations induced by the external factors were not reflected in the vitality index. 326 Nevertheless, the expected prediction error was very low for the vitality only model (0.08) and comparable to the model including both external factors and vitality (0.07). This demonstrated that the variability of the conditions within the captivity experiment is not expected to induce significant changes in the predicted survival rates when applied to the French data.

\begin{tabular}{lll}
\hline logit( $\pi$ ) & AIC & $\begin{array}{l}\text { Survival rate } \\
\text { prediction error }\end{array}$ \\
\hline (i) Intercept & 1734.2 & 0.21 \\
(ii) Vitality & 1615.1 & 0.08 \\
(iii) Vitality + Air T + Catch + TL & 1554.2 & 0.07
\end{tabular}


Table 3. Assessment of the survival proxy assumption for the vitality index. The mixture Weibull model was tested with different explanatory variables on the survival parameter $\pi$ : (i) no covariate, (ii) vitality, (iii) vitality + factors, (iv) factors. The survival rate prediction error was assessed by the cross-validated adjusted Brier score.

\subsubsection{Discard survival rates}

The distributions in vitality differed between the three trials (Table 4), with more individuals in 'Excellent' and 'Moribund' states in January than in November, and fewer in 'Excellent' and 'Good' states in July than in November. Consequently, the estimated survival rates are comparable in November and January (62.8\% and $66.6 \%$ respectively) and lower in July (45.2\%). The narrow confidence intervals for these estimates indicate good precision.

\begin{tabular}{lcccc}
\hline & Predicted vitality- & \multicolumn{2}{c}{ Observed vitality profiles in the discards } \\
& dependent survival rate & January-February & July & November \\
\hline Excellent & $90.2[83.3 ; 95.5]$ & 36.1 & 9.6 & 21.8 \\
Good & $71.9[62.2 ; 81.0]$ & 34.4 & 39.5 & 52.3 \\
Poor & $20.8[0.7 ; 37.3]$ & 19.1 & 44.9 & 25.4 \\
Moribund & $4.8[0.7 ; 11.4]$ & 10.4 & 6.0 & 0.5 \\
\hline Predicted discard survival rate & $62.8[54.9 ; 70.7]$ & $45.2[32.7 ; 55.3]$ & $66.6[57.0 ; 74.3]$ \\
\hline
\end{tabular}

Table 4. Estimated vitality-dependent survival rates from the experiments, observed distributions of vitality index in the different experiments (English fishery in January, French fishery in November and July), and corresponding estimated discard survival rates.

\subsection{Relationship between vitality index and potential survival drivers}

For each seasonal trial, the random effect at the haul level was significant (Table 5). The depth, tow duration, presence of injury-inducing elements and air exposure were negatively associated with plaice vitality in both French fishery trials. Furthermore, the interacting effects of the air exposure with the depth, tow duration and thermal shock in July and the air temperature in November accentuated the influence of these factors. Within the shorter ranges of depths and tow durations of the English trial, these factors did not appear significant. The effects of both injury-inducing elements and air exposure were not assessed in the English trial as they were not available. Nevertheless, the catch weight was measured in this particular case and was negatively associated to vitality. 
The temperature was systematically selected, but its effect varied across seasons. In January, the air temperature ranged between 4 and $12^{\circ} \mathrm{C}$ and was positively associated with vitality. In July, both air and bottom temperatures were much higher, and the vitality of fish was negatively associated to increasing thermal shock. In November, vitality level decreased slightly with air temperature over a very short range $\left(9-12.5^{\circ} \mathrm{C}\right)$. The fish vitality was also slightly increasing with the fish length on a short size range $(18-31 \mathrm{~cm})$ in July, and importantly on a larger size range $(19-60 \mathrm{~cm})$ in January.

The observed cumulated proportions of individuals in each vitality level and their predictions from the best model depending on each selected covariates were represented in Supplementary Material S2. The plots suggest that these models fit the data reasonably well. Nevertheless, the percentages of deviances explained by the covariates were very low in the three cases. Considering the amount of deviance explained by the random effect, most of this unexplained variations expressed at the individual level rather than at the haul level.

\begin{tabular}{llll}
\hline & January- & July & November \\
& February & & \\
\hline Random effect & $0.30(0.55)$ & $0.33(0.57)$ & $0.19(0.44)$ \\
Depth & 0 & $-0.14(0.21)$ & $-0.50(0.18)$ \\
Tow duration & 0 & $0.01(0.22)$ & $-0.18(0.20)$ \\
Catch weight & $-0.34(0.18)$ & NA & NA \\
Injury-inducing elements & NA & $-0.01(0.19)$ & -0.16 \\
Thermal shock & 0 & $-0.31(0.21)$ & 0 \\
Air T & $0.77(0.17)$ & 0 & $-0.24(0.20)$ \\
Wind & 0 & NA & NA \\
TL & $0.67(0.08)$ & $0.08(0.11)$ & 0 \\
Air exposure & NA & $-0.44(0.14)$ & $-0.28(0.14)$ \\
Depth*Air exposure & NA & $-0.14(0.15)$ & $0.23(0.14)$ \\
Tow duration*Air exposure & NA & $-0.20(0.18)$ & $0.29(0.12)$ \\
Thermal shock*Air exposure & NA & $-0.22(0.14)$ & 0 \\
Air T**Air exposure & NA & 0 & $-0.16(0.16)$ \\
TL*Air exposure & NA & $-0.15(0.11)$ & 0 \\
\hline & & 0 & 0 \\
\hline
\end{tabular}

Table 5. Estimates (SE) of the selected ordinal model for each seasonal trial. NA means that the covariate was not available on this trial. 


\subsection{Relationship between discard survival and selected factors}

368 The predicted vitality probabilities (Eq 5) were combined with the vitality-dependent survival 369 probability estimated from the captivity experiment (Table 3 ) to quantify the effect of the selected 370 factors on the discard survival (Figure 2). In January, survival was the most affected by the weight of 371 the catches, the low air temperature and the small length of the fish. Indeed, variations in catch weight 372 and air temperature were associated with up to $20 \%$ and $35 \%$ of mortality respectively. $42 \%$ of the 373 smallest fish from the English trial survived while $80 \%$ of the largest survived.

374 The main drivers of survival in July were the air exposure and thermal shock, as they were associated 375 with up to $20 \%$ and $30 \%$ respectively of mortality within their observation ranges. In November, the depth variations were associated to up to $25 \%$ of mortality.
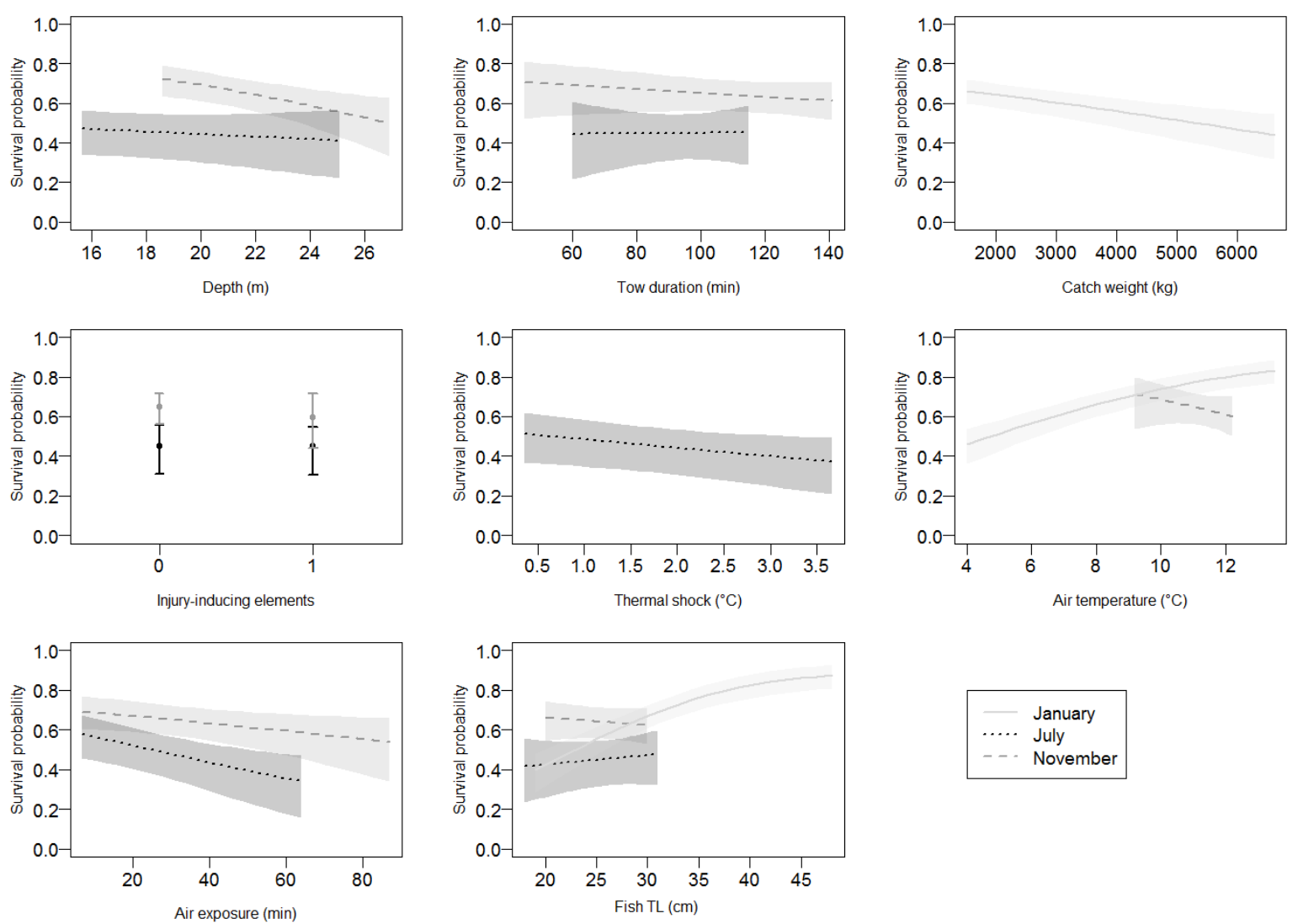

Figure 2. Discard survival as a function of each covariate in the selected proportional odds model based on cumulative logit link adjusted on ordinal vitality data in January-February (light grey lines), July (dotted black lines) and November (grey dotted lines). Shaded areas represent 95\%-confidence intervals estimated by non-parametric bootstrap. 


\subsection{Discard survival in captivity}

The survival of discarded European plaice has been predicted based on an ordinal fish vitality index as a proxy and a captive observation experiment. While for Moribund and Poor groups the mixture Weibull model may be too simplistic to explain some variations in the mortality rates, it was statistically valid and successfully managed to detect distinct asymptotes for the four vitality levels. Ninety per cent of the estimated mortality occurred before $120 \mathrm{~h}$ ( 5 days), thus the monitoring period appeared to be sufficient to estimate the asymptote of the survival function in line with other studies (Neat et al., 2009; Wassenberg and Hill, 1993). The resulting estimated survival rates for plaice were $62.8 \%$ (54.9-70.7\%) in January-February (direct estimation from English vessel); 66.6\% (57.0-74.3\%) in November and $45.2 \%$ (32.7-55.3\%) in July (proxy estimates from French vessels).

These estimated survival rates should be considered as the minimum discard survival rates that excludes the effect of predation. As they are more difficult to catch and handle than roundfish for seabirds, discarded plaice have less exposure to avian predation (Catchpole et al., 2015; Depestele et al., 2016). However, the effect of marine predation, which may be higher for discarded fish, due to impaired swimming abilities, increased exposure or to post-traumatic behaviour are not accounted for using captive observation method and therefore may overestimate survival (Raby et al., 2014). To account for marine predation, tagging experiments are required (Capizzano et al., 2016; Donaldson et al., 2008; Yergey et al., 2012). By contrast, the stressors associated with the captive observation method, including, handling, confinement, changes in temperature, dissolved oxygen and time taken to assess were likely to induce some experimental mortality, although control fish indicate this was minimal. In this study, while attempts were made to inform on experimental induced mortality, the control experiment took place in a different location to the treatment experiment and so different stressors were exerted to these groups. Moreover, the effect on survival of the on-board tanks used to transport the samples to the shore was not established. Though there was no obvious mortality associated with the interruptions or the on-shore transfer, the effects may not have been instantaneous. Therefore, the survival rates estimated in this project should be interpreted as the minimum discard survival estimates that do not account for induced experimental mortality, and exclude marine predation.

\subsection{Discards stressors}

The influence of stressors on fish during the catch and discarding processes was investigated within each seasonal trial separately to avoid potential influence of other unmeasured conditions associated to the trial. 
Despite the short range of the tow depths in the French shallow waters (16-27 m), mortality rates increased with depth. By contrast, the effect of the tow duration was marginal even on a 40-140 min range, in agreement with Van Beek et al. (1990). In a North Sea beam trawl fishery Depestele et al., (2014) identified a negative effect of increasing tow duration on plaice survival by considering shorter tow durations ( $<20 \mathrm{~min}$ vs. $92 \pm 12 \mathrm{~min}$ ). Though negatively significant in the French trials, the presence of oysters or stones in the catch had surprisingly barely no influence on survival. Including unmeasured factors such as the catch weight in future experiments in the French fishery would be relevant as it might also interact with the catch composition.

Air exposure was identified as a substantial influencing factor, especially in July where it was associated with an increase of up to $20 \%$ mortality. Hypoxia has been identified as one of the most important stressors in numerous studies and for a wide diversity of species (Benoît et al., 2013; Depestele et al., 2014; Methling et al., 2017; Morfin et al., 2017; Parker et al., 2003). Though plaice has stronger capacity to resist than other species owing to its ability to breathe via their skin (Steffensen et al., 1981), an experiment in the same fishing conditions in July demonstrated that between $7 \mathrm{~min}$ and $50 \mathrm{~min}$ spent on the deck the immediate mortality rate increased from 2\% to 25\% (Morfin et al., 2017). Also, the effect of fish length appeared very important in the English fishery, where larger individuals were observed. The vulnerability of smaller individuals found in Uhlmann et al., (2016) also occurred in a wide range of lengths.

These results suggest that plaice were vulnerable to thermal shock but also to extreme air temperatures at equal thermal shock, making them consequently even more vulnerable to extreme air temperatures. These findings are consistent with UhImann et al., (2016) who found a significant negative effect of temperature difference between SST and air at cold air temperatures. Van Beek et al. (1990) related higher survival at cooler SST between 8 and $18^{\circ} \mathrm{C}$. While a general model could not be fitted as the availability of covariates was not consistent across the three trials, these results are in agreement with the survival differences between trials. The lowest survival rate in July can be reasonably ascribed to the increase in air temperature. Despite that depths, tow durations and catch weights were much higher in the English fishery, the larger average size of sampled fish apparently balanced the effects of these stressors. Indeed, in this particular case fish were sampled in the whole catch instead of in the discards in the French trials. However, the corresponding discard survival rate was approximately $50 \%$, which remained substantial.

In the same area, Revill et al., (2013) found that survival of plaice was lower during the spawning period, occurring from the end of December to April with a peak in January-February (Houghton and Harding, 1976). As the length at $50 \%$ of maturity in this region $(26 \mathrm{~cm})$ is also the average observed 
length in January-February, the potential effect of the reproductive status on survival was accounted 449 for in this trial.

450 In practice, the survival rate could be increased in this fishery essentially by reducing the air exposure 451 duration before the fish are returned to the sea, particularly because of the associated interaction with 452 air temperature. Other studies already proposed and demonstrated the usefulness of a sorting table 453 and evacuation gutter on board in Nephrops norvegicus fishery (Mérillet et al., 2017). The effect of 454 extreme air temperatures could also be mitigated by installing roofs of insulated containers to protect 455 the fish from direct sunlight exposure.

\subsection{Discard survival rate in commercial conditions}

This study provides a first estimate for the discard survival of plaice in the English Channel coastal otter trawl fishery in conditions representative of usual commercial fishing activities and for three periods of the year during which commercial fishing takes place. These rates are in the upper range of the rates obtained in coastal beam and otter trawling fisheries in the English Channel and the North Sea (Depestele et al., 2014; Methling et al., 2017; Revill et al., 2013; Uhlmann et al., 2016).

For two of the three trials (the French fishery), the survival was estimated by combining the discard fish vitality distribution with the vitality-dependent survival rates estimated from the captivity experiment in the other trial (English fishery). The high correlation between vitality and survival in captivity and the low expected predictive error of the survival rate clearly demonstrated the relevance of this proxy. The air temperature, the catch weight and the fish length explained some remaining variability not explained by the vitality index but the predictive performance of the vitality index was barely influenced by these conditions in the captivity experiment. As the ranges of the catch weight, air temperature and tow duration were different in the French fishery, one could argue that the assumptions of the proxy are undermined. However, the thermal shock was comparable between trials and catch weights and tow durations were much higher in the captivity experiment, thereby any departure from the proxy assumption would have underestimated the survival rate in the French experiment. From a management perspective this is preferable, it suggests that the survival could actually be higher in the French trials than indicated by the proxy and so reducing the risk that any exemption would be awarded on overestimated survival levels. discarded plaice at other times differ substantially from the ones in the trial or if the effect of those 
may not be applicable to vitality data collected at those other times. The analyses presented here suggest that vitality is a dependable and important predictor of survival across a broad range of environmental conditions, but further research on the stability of the vitality-survival relationship within a fishery should be a priority for this field, as this is likely to be true for a majority of similar discard mortality studies.

Extrapolating these estimates to the fishery also requires assuming that the stress factors exerted on the fish in the wider fishery are the same as those from the trips during which the survival experiments were conducted. This can be assessed by sampling vitality values from the broader fishery by at-sea observers as in this study. Vitality assessment may be observer dependent or catch/trial dependent, i.e. the appreciation of weak versus vigorous movement may be influenced by the status of the other individuals observed. In principle, the incorporation of a random effect in the model for these data should account for this subjectivity (Benoît et al., 2010). Other proxies may be less subjective, such as reflex action mortality predictors (RAMP) (Davis, 2010; Davis and Ottmar, 2006; Stoner, 2012), though Uhlmann et al., (2016) also detected some observer effect. Furthermore, they require preliminary experiments on unstressed specimens to determine the relationship between survival and each reflex. Further analyses comparing both kind of index would be relevant to determine the relative pertinence of these proxies. An alternative for fishery extrapolation is to estimate the distribution of the vitality in the fishery by modelling vitality as a function of relevant covariates and estimates of the distributions for these covariates in the fishery (Benoît et al., 2013, 2010). While the potential effects due to the variability of the crews and vessels were not assessed, this study covered a broad range of the conditions that the fishery may encounter.

\section{Acknowledgements}

This work was part of the ENSURE project supported by France Filière Pêche and the Direction des Pêches Marines et de l'Aquaculture and received funding from Defra, UK. The authors thank the crew of Mon Petit Celestin and Guiding Light III for their help on board to conduct the experiments. They also thank Camille Vogel and Ruth Hicks for their help on-board the fishing vessels.

\section{Supplementary material}

S1. Description of the simulations used to estimate the confidence intervals in the discard survival rates S2. Predicted cumulative probabilities of the vitality index depending on each covariate in the selected proportional odds model 
Akaike, H., 1981. Likelihood of a model and information criteria. J. Econom. 16, 3-14.

Arlot, S., Celisse, A., 2010. A survey of cross-validation procedures for model selection. Stat. Surv. 4, 40-79.

Benoît, H.P., Capizzano, C.W., Knotek, R.J., Rudders, D.B., Sulikowski, J.A., Dean, M.J., Hoffman, W., Zemeckis, D.R., Mandelman, J.W., 2015. A generalized model for longitudinal short- and longterm mortality data for commercial fishery discards and recreational fishery catch-andreleases. ICES J. Mar. Sci. J. Cons. fsv039. doi:10.1093/icesjms/fsv039

Benoît, H.P., Hurlbut, T., Chassé, J., 2010. Assessing the factors influencing discard mortality of demersal fishes using a semi-quantitative indicator of survival potential. Fish. Res. 106, 436447. doi:10.1016/j.fishres.2010.09.018

Benoît, H.P., Hurlbut, T., Chassé, J., Jonsen, I.D., 2012. Estimating fishery-scale rates of discard mortality using conditional reasoning. Fish. Res. 125-126, 318-330. doi:10.1016/j.fishres.2011.12.004

Benoît, H.P., Plante, S., Kroiz, M., Hurlbut, T., 2013. A comparative analysis of marine fish species susceptibilities to discard mortality: effects of environmental factors, individual traits, and phylogeny. ICES J. Mar. Sci. J. Cons. 70, 99-113. doi:10.1093/icesjms/fss132

Breen, M., Isaksen, B., Ona, E., Pedersen, A.O., Pedersen, G., Saltskår, J., Svardal, B., Tenningen, M., Thomas, P.J., Totland, B., others, 2012. A review of possible mitigation measures for reducing mortality caused by slipping from purse-seine fisheries. ICES CM 100, 12.

Broadhurst, M.K., Suuronen, P., Hulme, A., 2006. Estimating collateral mortality from towed fishing gear. Fish Fish. 7, 180-218. doi:10.1111/j.1467-2979.2006.00213.x

Byrd, R.H., Lu, P., Nocedal, J., Zhu, C., 1995. A limited memory algorithm for bound constrained optimization. SIAM J. Sci. Comput. 16, 1190-1208.

Capizzano, C.W., Mandelman, J.W., Hoffman, W.S., Dean, M.J., Zemeckis, D.R., Benoît, H.P., Kneebone, J., Jones, E., Stettner, M.J., Buchan, N.J., Langan, J.A., Sulikowski, J.A., 2016. Estimating and mitigating the discard mortality of Atlantic cod (Gadus morhua) in the Gulf of Maine recreational rod-and-reel fishery. ICES J. Mar. Sci. J. Cons. fsw058. doi:10.1093/icesjms/fsw058

Castro, M., Araújo, A., Monteiro, P., Madeira, A.M., Silvert, W., 2003. The efficacy of releasing caught Nephrops as a management measure. Fish. Res. 65, 475-484. doi:10.1016/j.fishres.2003.09.033

Catchpole, T., Randall, P., Forster, R., Smith, S., Ribeiro Santos, A., Armstrong, F., Hetherington, S., Bendall, V., Maxwell, D., 2015. Estimating the discard survival rates of selected commercial fish species (plaice - Pleuronectes platessa) in four English fisheries (Cefas report No. MF1234). CEFAS.

Christensen, R.H.B., 2015. ordinal: Regression Models for Ordinal Data.

Cornou, A.-S., Quinio-Scavinner, M., Delaunay, D., Dimeet, J., Goascoz, Nicolas, Dube, Benoit, Fauconnet, Laurence, Rochet, Marie-Joelle, 2015. Observations à bord des navires de pêche professionnelle. Bilan de l'échantillonnage 2014. doi:10.13155/39722

Davis, M.W., 2010. Fish stress and mortality can be predicted using reflex impairment. Fish Fish. 11, 1-11. doi:10.1111/j.1467-2979.2009.00331.x

Davis, M.W., 2002. Key principles for understanding bycatch discard mortality. Can. J. Fish. Aquat. Sci. 59, 1834-1843. doi:10.1139/f02-139

Davis, M.W., Olla, B.L., 2002. Mortality of lingcod towed in a net as related to fish length, seawater temperature, and air exposure: a laboratory bycatch study. North Am. J. Fish. Manag. 22, 1095-1104. doi:10.1577/1548-8675(2002)022<1095:MOLTIA>2.0.CO;2

Davis, M.W., Ottmar, M.L., 2006. Wounding and reflex impairment may be predictors for mortality in discarded or escaped fish. Fish. Res. 82, 1-6. doi:10.1016/j.fishres.2006.09.004 
Depestele, J., Desender, M., Benoît, H.P., Polet, H., Vincx, M., 2014. Short-term survival of discarded target fish and non-target invertebrate species in the "eurocutter" beam trawl fishery of the southern North Sea. Fish. Res. 154, 82-92. doi:10.1016/j.fishres.2014.01.018

Depestele, J., Dorémus, G., Laffargue, P., Stienen, E.W.M., Rochet, M.-J., 2016. Favorites and leftovers on the menu of scavenging seabirds: modelling spatio-temporal variation in discard consumption. Can. J. Fish. Aquat. Sci. doi:10.1139/cjfas-2015-0326

Donaldson, M.R., Arlinghaus, R., Hanson, K.C., Cooke, S.J., 2008. Enhancing catch-and-release science with biotelemetry. Fish Fish. 9, 79-105. doi:10.1111/j.1467-2979.2007.00265.x

Farewell, V.T., 1982. The Use of Mixture Models for the Analysis of Survival Data with Long-Term Survivors. Biometrics 38, 1041-1046. doi:10.2307/2529885

Gerds, T.A., Schumacher, M., 2006. Consistent Estimation of the Expected Brier Score in General Survival Models with Right-Censored Event Times. Biom. J. 48, 1029-1040. doi:10.1002/bimj.200610301

Giomi, F., Raicevich, S., Giovanardi, O., Pranovi, F., Muro, P.D., Beltramini, M., 2008. Catch me in winter! Seasonal variation in air temperature severely enhances physiological stress and mortality of species subjected to sorting operations and discarded during annual fishing activities. Hydrobiologia 606, 195-202. doi:10.1007/s10750-008-9336-x

Gu, Y., Sinha, D., Banerjee, S., 2011. Analysis of Cure Rate Survival Data Under Proportional Odds Model. Lifetime Data Anal. 17, 123-134. doi:10.1007/s10985-010-9171-z

Harris, R.R., Ulmestrand, M., 2004. Discarding Norway lobster (Nephrops norvegicus L.) through low salinity layers - mortality and damage seen in simulation experiments. ICES J. Mar. Sci. J. Cons. 61, 127-139. doi:10.1016/j.icesjms.2003.08.002

Houghton, R., Harding, D., 1976. Plaice of English-Channel - Spawning and Migration. J. Cons. 36, 229-239.

Kaplan, E.L., Meier, P., 1958. Nonparametric Estimation from Incomplete Observations. J. Am. Stat. Assoc. 53, 457-481. doi:10.1080/01621459.1958.10501452

Macbeth, W.G., Broadhurst, M.K., Paterson, B.D., Wooden, M.E.L., 2006. Reducing the short-term mortality of juvenile school prawns (Metapenaeus macleayi) discarded during trawling. ICES J. Mar. Sci. J. Cons. 63, 831-839. doi:10.1016/j.icesjms.2006.03.008

McCullagh, P., 1980. Regression Models for Ordinal Data. J. R. Stat. Soc. Ser. B Methodol. 42, 109142.

Méhault, S., Morandeau, F., Kopp, D., 2016. Survival of discarded Nephrops norvegicus after trawling in the Bay of Biscay. Fish. Res. 183, 396-400. doi:10.1016/j.fishres.2016.07.011

Mérillet, L., Kopp, D., Morandeau, F., Méhault, S., Rimaud, T., Piton, C., 2017. Assessment of the survival rate of unwanted catches of Norway lobster Nephrops norvegicus caught by bottom trawling in the Bay of Biscay (Scientific report). IFREMER.

Methling, C., Skov, P.V., Madsen, N., 2017. Reflex impairment, physiological stress, and discard mortality of European plaice Pleuronectes platessa in an otter trawl fishery. ICES J. Mar. Sci. doi:10.1093/icesjms/fsx004

Morfin, M., Méhault, S., Benoît, H.P., Kopp, D., 2017. Narrowing down the number of species requiring detailed study as candidates for the EU Common Fisheries Policy discard ban. Mar. Policy 77, 23-29. doi:10.1016/j.marpol.2016.12.003

Neat, F.C., Breen, M., Cook, R.M., Gibb, I.M., Wright, P.J., 2009. Electronic tags reveal behaviour of captured and discarded fish. J. Fish Biol. 74, 715-721. doi:10.1111/j.1095-8649.2008.02159.x

Neilson, J.D., Waiwood, K.G., Smith, S.J., 1989. Survival of Atlantic Halibut (Hippoglossus hippoglossus) Caught by Longline and Otter Trawl Gear. Can. J. Fish. Aquat. Sci. 46, 887-897. doi:10.1139/f89-114

Parker, S.J., Rankin, P.S., Hannah, R.W., Schreck, C.B., 2003. Discard Mortality of Trawl-Caught Lingcod in Relation to Tow Duration and Time on Deck. North Am. J. Fish. Manag. 23, 530542. doi:10.1577/1548-8675(2003)023<0530:DMOTCL>2.0.CO;2 
641

642

Raby, G.D., Packer, J.R., Danylchuk, A.J., Cooke, S.J., 2014. The understudied and underappreciated role of predation in the mortality of fish released from fishing gears. Fish Fish. 15, 489-505. doi:10.1111/faf.12033

Revill, A.S., Broadhurst, M.K., Millar, R.B., 2013. Mortality of adult plaice, Pleuronectes platessaand sole, Solea solea discarded from English Channel beam trawlers. Fish. Res. 147, 320-326. doi:10.1016/j.fishres.2013.07.005

Steffensen, J.F., Lomholt, J.P., Johansen, K., 1981. The relative importance of skin oxygen uptake in the naturally buried plaice, pleuronectes platessa, exposed to graded hypoxia. Respir. Physiol. 44, 269-275. doi:10.1016/0034-5687(81)90022-0

Stoner, A.W., 2012. Evaluating vitality and predicting mortality in spot prawn, Pandalus platyceros, using reflex behaviors. Fish. Res. 119, 108-114. doi:10.1016/j.fishres.2011.12.014

Tenningen, M., Vold, A., Olsen, R.E., 2012. The response of herring to high crowding densities in purse-seines: survival and stress reaction. Ices J. Mar. Sci. 69, 1523-1531. doi:10.1093/icesjms/fss114

Uhlmann, S.S., Broadhurst, M.K., 2015. Mitigating unaccounted fishing mortality from gillnets and traps. Fish Fish. 16, 183-229. doi:10.1111/faf.12049

Uhlmann, S.S., Theunynck, R., Ampe, B., Desender, M., Soetaert, M., Depestele, J., 2016. Injury, reflex impairment, and survival of beam-trawled flatfish. ICES J. Mar. Sci. J. Cons. fsv252. doi:10.1093/icesjms/fsv252

Van Beek, F.A., Van Leeuwen, P.I., Rijnsdorp, A.D., 1990. On the survival of plaice and sole discards in the otter-trawl and beam-trawl fisheries in the North Sea. Neth. J. Sea Res. 26, 151-160. doi:10.1016/0077-7579(90)90064-N

Wassenberg, T., Hill, B., 1993. Selection of the Appropriate Duration of Experiments to Measure the Survival of Animals Discarded from Trawlers. Fish. Res. 17, 343-352. doi:10.1016/01657836(93)90134-S

Wassenberg, T.J., Milton, D.A., Burridge, C.Y., 2001. Survival rates of sea snakes caught by demersal trawlers in northern and eastern Australia. Biol. Conserv. 100, 271-280. doi:10.1016/S00063207(01)00031-3

Yergey, M.E., Grothues, T.M., Able, K.W., Crawford, C., DeCristofer, K., 2012. Evaluating discard mortality of summer flounder (Paralichthys dentatus) in the commercial trawl fishery: Developing acoustic telemetry techniques. Fish. Res. 115, 72-81. doi:10.1016/j.fishres.2011.11.009

Supplementary material

\section{S1. Description of the simulation procedure used to estimate the confidence intervals in the discard} survival rates

The discard survival rate was estimated according to Eq 2 and can be re-written as follow: 
$651 \hat{R}(t)=\frac{1}{m} \sum_{s=1}^{m} \frac{1}{n_{s}} \sum_{j=1}^{n_{s}} \hat{S}_{M}\left(t \mid V=v_{j}\right)=\frac{1}{m} \sum_{s=1}^{m} \frac{1}{n_{s}} \sum_{v=1}^{4} n_{s, v} \hat{S}_{M}(t \mid V=v)=\frac{1}{m} \sum_{s=1}^{m} \sum_{v=1}^{4} w_{s, v} \hat{S}_{M}(t \mid V=v)$

652

653

654

655

656

657

658

659

660

661

662

663

664

665

666

667

668

669

670

671

672

673

674

675

676

677

678

679

680

$m$ : number of hauls; $n_{s}$ : number of individuals in haul $s$

$n_{s, v}$ : number of individuals in haul $s$ with vitality level $v$;

$w_{s, v}:$ proportion of individuals in haul $s$ with vitality level $v$;

Two sources of variability were estimated: the variability emerging from the captivity data, propagated to the estimate of the survival functions $\hat{S}_{M}\left(t \mid V=v_{j}\right), \mathrm{j}=1, . ., 4$ and from the vitality data.

At each iteration $k$ of the algorithm:

(i) Variability in the discard survival rates by vitality level from the captivity experiment

A parametric bootstrap based on Monte Carlo simulation was done to estimate the variability in survival rates from the captivity experiment. Based on asymptotically normal behavior of the maximum likelihood estimators, the regressions parameters were simulated according to a multivariate Gaussian distribution:

$$
\beta=N(\widehat{\boldsymbol{\beta}}, \widehat{\boldsymbol{\Sigma}})
$$

where $\widehat{\boldsymbol{\beta}}=\left(\hat{\boldsymbol{\beta}}_{v}^{\pi}, \widehat{\beta}_{v}^{\alpha}, \hat{\boldsymbol{\beta}}_{v}^{\gamma}\right)$ and $\widehat{\boldsymbol{\Sigma}}$ are respectively the maximum likelihood estimates and the covariance matrix of the selected model.

$\operatorname{logit}\left(\hat{\pi}_{v}\right)=\widehat{\beta}_{v}^{\pi}$

$\log \left(\hat{\alpha}_{v}\right)=\widehat{\beta}_{v}^{\alpha}$

$$
\log \left(\hat{\gamma}_{v}\right)=\hat{\beta}_{v}^{\gamma}
$$

For each simulation, the survival rate in each vitality group $\hat{S}_{M}(t \mid V=v)$ was calculated according to Eq 1 and 2.

681 

capture the variability due to the selection of fish in each haul. The resulting proportions $w_{s, v}$ of fish in each vitality group $v$ and sampled haul $s$ were calculated. At each iteration an average survival rate was calculated from Eq 3 using $w_{s, v}$ and $\hat{S}_{M}(t \mid V=v)$, $v=1, \ldots, 4, s=1, \ldots, m$.

687

688 These steps were repeated 5000 times to generate a distribution of $R^{*}$ which reflects the uncertainty 689 in both vitality and captivity data.

690

691 S2. Predicted cumulative probabilities of the vitality index, $P(V \leq j)$ for $j=1, \ldots, 3$, as a function of 692 each covariate in the selected proportional odds model based on cumulative logit link fit to ordinal 693 vitality data from each season. The other covariates were set to their means when making the 694 predictions. The vitality index categories were expressed in numerical values; 4: 'Moribund', 3: 'Poor', 695 2: 'Good', 1: 'Excellent'. Dashed lines are pointwise 95\%-confidence intervals estimated by non696 parametric bootstrap. 

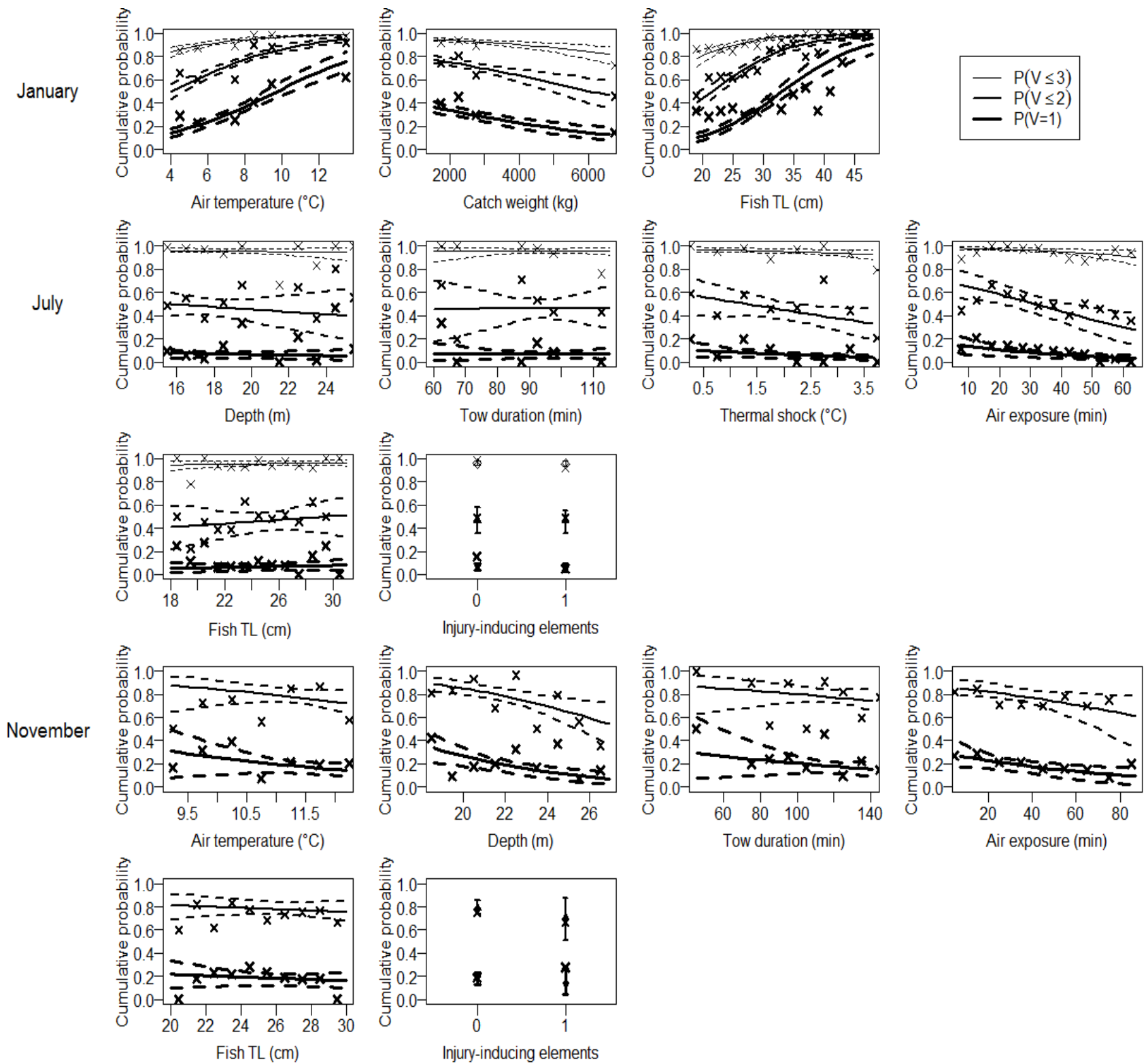